\title{
A taxonomic note of Ageratina altissima and Eupatorium rugosum (Asteraceae: Eupatorieae)
}

\author{
Sang-Hun $\mathbf{O H}^{*}$ \\ Department of Biology, Daejeon University, Daejeon 34520, Korea \\ (Received 31 August 2019; Revised 25 September 2019; Accepted 27 September 2019)
}

\begin{abstract}
Eupatorium rugosum Houtt. is known to be an alien invasive species and is listed as an ecosystem disturbance species in Korea. There is also an eastern North American species Ageratina altissima (L.) R. M. King \& H. Rob. similarly dispersed in Korea. This article aims to clarify the taxonomic confusion regarding the species. The two names refer to the same species originally described as Ageratum altissimum by Linnaeus in his Species Plantarum. Ageratum altissimum was transferred to the genus Eupatorium and later to Ageratina. Eupatorium rugosum is the replacement name in Eupatorium because of E. altissimum L., an existing name based on the different type. When the species was transferred to Ageratina, A. altissima was published based on its basionym, as the epithet "altissima" was available in the genus. It seems that taxonomic confusion regarding the species in Korea is due to the recognition of the names as different taxa. Ageratina altissima is the correct name for the species based on morphological and molecular data.
\end{abstract}

Keywords: Ageratum, Ageratina, Eupatorium, Ageratina altissima, taxonomic confusion

서양등골나물(Eupatorium rugosum Houtt.)은 국화과 등 골나물족(tribe Eupatorieae)에 속하는 북아메리카 원산 다 년생 초본으로 한반도에는 중부 지방에 귀화한 식물로 인 식된다(Kim, 2007, 2019). 서양등골나물은 Lee and Yim (1978)에 의해 처음으로 귀화종으로 보고되었으며, 현재 남산, 관악산, 우면산 등의 서울 지역의 산지 등산로에 집 중적으로 분포하고 인천, 의정부, 성남, 수원을 포함한 경 기도 일대에 퍼져 있다. 서양등골나물은 다양한 토양 환 경 및 광 조건에서 생육하면서 높은 번식력을 지녀 생태 계 교란 생물로 지정되어 있다(http://www.me.go.kr).

저자는 한반도에 분포하는 등골나물족의 분류학적 연 구를 수행하는 과정에서 서양등골나물과 미국등골나물 (Ageratina altissima (L.) R. M. King \& H. Rob.)에 대한 분류 학적 혼란이 있어 이를 명확히 해결할 필요가 있다고 판 단하였다. $\operatorname{Kim}(2007,2019)$ 은 미국등골나물(A. altissima) 을 등골나물족에 포함되는 북아메리카 원산 다년생 초본 의 귀화종으로 인식하면서 서양등골나물(E. rugosum)과 독 립된 종으로 처리하고 있다. Lee (2003)와 Park (2009)은 서 양등골나물을 E. rugosum으로 인식하고 있는 반면 미국등 골나물에 대해서는 언급하지 않고 있으며, Lee(2006)는 서
양등골나물에 대한 언급은 없으면서 미국등골나물을 Eupatorium aromaticum L.로 인식하고 있다. 한편, 일부 문헌 (Kim et al., 2014)에서는 서양등골나물의 학명으로 $A$. altissima를 사용하고 있는 등 현재 우리나라에서는 미국 등골나물과 서양등골나무에 대한 분류학적 실체가 명확 하게 인식되지 않은 실정이다. 서양등골나물처럼 외래종 이 국내로 유입된 후 급속히 퍼져 자생 식물의 생태계를 위협하는 외래 침입종(alien invasive species) (IUCN, 2000) 의 경우 이에 대한 체계적인 관리를 위해서 종의 분류학 적 정체를 명확히 파악하여 정보를 제공하는 것은 식물계 통분류학의 중요한 역할 중 하나이다.

본 논문에서는 미국등골나물과 서양등골나물의 분류 학적 내력을 재고하여 서양등골나물과 미국등골나물이 동일한 분류군임을 설명하고 형태적 특징에 근거하여 국 내에서 혼란이 있는 이들의 분류학적 실체를 명확히 밝히 고자 한다.

\section{재료 및 방법}

국립생물자원관 관속식물표본관 $(\mathrm{KB})$ 과 국립수목원 산

*Author for correspondence: soh42@dju.kr Open Access http://e-kjpt.org, (C) 2019 the Korean Society of Plant Taxonomists. This is an open-access article distributed under the terms of the Creative Commons Attribution Non-Commercial License
(http://creativecommons.org/licenses/by-nc/4.0) which permits unrestricted non-commercial use, distribution, and reproduction in any medium, provided the original work is properly cited. 
림생물표본관(KH)에 소장된 A. altissima와 E. rugosum의 약 100 여 점의 표본 및 근연 분류군 Ageratum L. 및 Eupatorium L.에 속하는 종)의 약 200 여 점의 표본을 대상 으로 형태 형질 및 분포지를 분석하였다. 또한, A. altissima 와 E. rugosum의 원기재문 및 북아메리카와 국내에서 발 간된 등골나물족의 분류학적 처리가 포함된 문헌 (Linnaeus, 1753, 1774; Houttuyn, 1779; Reichard, 1780; Linnaeus f., 1781; King and Robinson, 1970, 1987; Clewell and Wooten, 1971; Gleason and Cronquist, 1991; Lee, 2003; Lee, 2006; Nesom, 2006; Kim, 2007, 2019)을 조사하여 종의 실체 및 분류학적 내력을 파악하였다.

\section{결과 및 고찰}

Eupatorium rugosum은 Ageratina altissima의 명명법적 이 명(nomenclatural synonym)으로 이 두 이름은 동일한 분류 군을 지칭한다. 이 종은 Linnaeus (1753)에 의해 최초로 기 재되었다. Linnaeus (1753)는 그의 저서 "Species Plantarum" 에 등골나물아재비속(Ageratum)을 설정하고 캐나다와 미 국 버지니아에 자생하는 식물을 바탕으로 A. altissimum L. 을 기재하였다. 이후 Linnaeus (1774)는 A. altissimum을 Eupatorium (등골나물속)으로 전이시켜 E. altissimum (L.) L.을 발표하였는데, 이것은 그 자신(Linnaeus, 1753)이 이 미 전혀 다른 기준표본에 근거해 공표한 E. altissimum L.의 후일동음명(later homonym)으로서 비합법명(illegitimate name)이다. 이 문제를 해결하기 위해 Houttuyn (1779)은 Eupatorium rugosum Houtt.를 대체명(replacement name)으 로 공표하였는데, 이 이름이 현재 국내에서 서양등골나물 의 학명으로 흔히 사용되고 있다(Lee and Yim, 1978; Lee, 2003; Kim, 2007, 2019; Park, 2009). 한편, Reichard (1780)와 Linnaeus의 아들인 Linnaeus f. (1781)도 Houttuyn과 유사하 게 A. altissimum을 Eupatorium으로 전이시키면서 $E$. urticaefolium Reichard와 E. ageratoides L. f.를 대체명으로 각각 공표하였다. 그러나 이 이름들은 모두 E. rugosum에 대해 선취권(priority)이 없다.
King and Robinson (1970)은 꽃과 열매의 형태적 특징으 로 Eupatorium과 Ageratina Spach을 뚜렷이 구분할 수 있다 고 보았다. Eupatorium은 화관열편이 전연이고, 화주 기부 에 털이 있으며, 화관과 수과 표면에 선점(gland)이 있고, 수과기부부속체(carpopodium)가 불분명하다는 것이다. 이 를 바탕으로 Eupatorium에 분류되어 왔던 많은 종들을 Ageratina로 전이시키면서 Ageratina의 분류체계를 재정립 하였는데, E. rugosum도 Ageratina로 전이되었다(King and Robinson, 1970). 이 때, E. rugosum의 원명(basionym)의 종 소명인 'altissimum'은 Ageratina에서 사용되고 있지 않았 으므로 이 종소명을 바탕으로 한 신조합명인 A. altissima 가 공표되었다(King and Robinson, 1970).

등골나물족에 대한 최근의 연구 결과는 Ageratina와 Eupatorium 이 서로 독립된 속임을 지지하고 있다. 분자형질 을 이용한 분자계통학적 연구에서 Ageratina는 Eupatorium 과 유연관계가 멀고, 독립된 단계통군인 것으로 밝혀졌다 (Schilling et al., 1999; Schmidt and Schilling, 2000). 염색체 의 기본수(base chromosome number)에 의해서도 Ageratina 와 Eupatorium은 뚜렷하게 차이가 난다. Ageratina는 염색 체의 기본수가 $x=17$ 인 반면, Eupatorium은 $x=10$ 이다 (King et al., 1976; King and Robinson, 1987). 즉, Linnaeus (1753)가 처음으로 기재했던 Ageratum altissimum은 형태 형질(King and Robinson, 1970) 및 분자 형질(Schilling et al., 1999; Schmidt and Schilling, 2000)에 근거해 Ageratina속에 속하고(Table 1), 이 식물의 정명은 A. altissima이다.

Ageratina altissima에는 2변종(var. altissima 및 var. roanense Small)이 인식되고 있다(Nesom, 2006). 이 두 변종 은 총포편(phyllary)의 길이 및 선단부의 형태에 의해서 구 분되는데 우리나라에 침입한 개체들은 var. altissima에 해 당한다.

Lee (2006)에서 서양등골나물로 인식된 E. aromaticum은 Ageratina aromatica (L.) Spach로서 Ageratina의 기준종 (type species)이다. Ageratina aromatica는 A. altissima에 비 해 엽병이 $1 \mathrm{~cm}$ 미만으로 매우 짧고 잎의 크기가 상대적으 로 더 작다(Nesom, 2006). Lee (2006)에 제시되어 있는 사진

Table 1. Comparison of diagnositc characteristics of Ageratina, Eupatorium, and Ageratina altissimum.

\begin{tabular}{lccc}
\hline \multirow{2}{*}{ Character } & & Taxa & \\
\cline { 2 - 4 } & Ageratina & Eupatorium & A. altissima \\
\hline Gland on leaves & Absent in most species & Present in most species & Absent \\
No. of florets per head & $10-60$ & 5 & $15-25$ \\
Style base pubescence & Glabrous & Puberulent & Glabrous \\
Gland on corolla & Present & Absent & Present \\
Gland on cypselae & Present & Absent & Present \\
Carpopodium & Present & Obscure & Present \\
Chromosome number & $x=10$ & $x=17$ & $n=17$ \\
\hline
\end{tabular}


과 기재문에 근거하면 Lee (2006)가 지칭하는 서양등골나 물은 A. altissima인 것으로 사료된다. 또한, 저자가 관찰한 표본 및 야외에서 조사한 개체들은 모두 A. altissima였다 는 점에서 Lee (2006)의 E. aromatica는 학명을 잘못 적용한 것으로 추정된다.

Ageratina altissima는 벤조 퓨란계 화합물(benzofurans)을 함유하고 있어서 유독식물이다. Ageratina altissima를 먹 은 소에서 얻은 우유를 섭취할 때 유유에 함유된 벤조 퓨 란으로 인해 우유병(milk sickness)이 발병할 수 있는 것으 로 알려져 있다(King and Robinson, 1987). 우리나라에서는 젖소를 거의 방목하지 않고, 현재까지 A. altissima가 방목 지에 퍼진 기록은 없다. 그러나 A. altissima의 외형이 부드 럽고 “나물”로 부르기 때문에 식용식물로 오해할 소지가 있어 주의가 필요하다. 또한, A. altissima는 생태계 교란 생 물로 전파 속도가 매우 빠르기 때문에 지역별로 개체를 제거하는 등 관리가 필요하다. Ageratina altissima가 주로 등산로 주변에 자라고, 뿌리가 깊지 않으며, 꽃이 피지 않 더라도 쉽게 구분할 수 있어 퇴치작업이 어렵지 않을 것 이다.

Ageratina altissima와 E. rugosum이 동일한 종이므로 통 일된 국명은 무엇을 사용해야 할까? 세가지 방안을 생각 해 볼 수 있다. 첫째는 학명에 따라 국명을 부여하는 것이 다. 앞에서 서술한 바와 같이 이 식물의 정명은 A. altissima 이므로 이 학명에 부여된 국명인 미국등골나물(Kim, $2007,2019)$ 을 쓰는 것이다. 둘째는 서양등골나물에 사용 한 E. rugosum의 학명을 수정하는 것이다. 전자는 학명을 기준으로 국명을, 후자는 국명을 기준으로 학명을 변경하 는 것으로 볼 수 있다. 셋째는 A. altissima에 대해 2 개 국명 을 함께 쓰는 것이다. 국명에 대해 명확히 정해진 명명법 은 없다. 그러나 하나의 종에 대해서 여러 개의 국명을 사 용하는 것은 더 많은 혼란을 초래할 수 있어 세번째 방안 은 최선이 아니다. “서양등골나물”이 “미국등골나물”보 다 여러 문헌에서 더 많이 사용되고 있고, 이 외래 식물의 국내 분포를 최초 보고한 문헌에서 “서양등골나물”을 사 용했던 점을 고려할 때 A. altissima의 국명은 서양등골나 물로 적용하는 것이 타당하다. 이에 따라 Ageratina에 대한 국명도 서양등골나물속으로 사용하여야 할 것이다. 서양 등골나물속은 아메리카대륙에 자생하는 약 250 종을 포함 하는데, 우리나라에는 서양등골나물 1종만 분포한다.

린네 표본관(The Linnaean Herbarium, LINN)에는 서양등 골나물의 원명인 Ageratum altissimum 으로 등록된 표본이 없다. 그러나 Eupatorium altissimum으로 동정된 표본은 2 점(LINN 978.7과 LINN 978.25)이 있는데, LINN 978.25는 형태적으로 A. altissima와 일치하고 LINN 978.7은 E. altissimum과 일치한다. LINN 978.7 표본에는 속명을 표시 하지 않고 단지 "altissimum"이라고 적힌 린네의 글씨와 그 의 아들(Linnaeus, f.)이 추가한 “Ageratoides"라는 주석 (annotation)이 있다. 이 주석에 쓰인 이름은 Linnaeus $\mathrm{f}$.
(1781)가 Ageratum altissimum을 Eupatorium속으로 분류할 때 사용했던 대체명이므로 이 표본이 A. altissimum의 기준 표본으로 여겨진다(Clewell and Wooten, 1971).

\section{Taxonomy}

Ageratina altissima (L.) R. M. King \& H. Rob., Phytologia 19: 212, 1970. Ageratum altissimum L., Sp. Pl. 839, 1753; Eupatorium altissimum (L.) L., Syst. Veg. ed. 13, 614, 1774, nom. illeg.; E. rugosum Houtt., Nat. Hist. 2(10): 558, 1779, nom. nov.; E. urticaefolium Reichard, Syst. Pl. 3: 719, 1780, nom. nov., nom. illeg.; E. ageratoides L. f., Suppl. Pl. 355, 1781, nom. nov., nom. illeg.-TYPE: LINN 978.25 (holotype: LINN, http://linnean-online.org/9969/).

국명: 서양등골나물.

영명: White snakeroot.

분포: 캐나다 및 미국 동부 지역에 자생; 서울, 경기도의 산지 등산로 주변, 화단 등에 귀화종으로 분포.

ORCID: Sang-Hun OH https://orcid.org/0000-0001-8778-4458

\section{Acknowledgments}

The author thanks staff of KB and KH, who generously allowed to examine their specimens and two anonymous reviewers for their constructive comments. This work was supported by a grant from the National Institute of Biological Resources (NIBR), founded by the Ministry of Environment (MOE) of the Republic of Korea (NIBR201903101).

\section{Conflict of Interest}

The author declares that there are no conflicts of interest.

\section{Literature Cited}

Clewell, A. F. and J. W. Wooten. 1971. A revision of Ageratina (Compositae: Eupatorieae) from eastern North America. Brittonia 23: 123-143.

Gleason, H. A. and A. Cronquist. 1991. Manual of Vascular Plants of Northeastern United States and Adjacent Canada. The New York Botanical Garden, New York, NY, 993 pp.

Houttuyn, M. 1779. Natuurlijke Historie, 2nd part, 10th fascicle. de Erven van F. Houttuyn, Amsterdam, 828 pp.

IUCN (International Union for Conservation of Nature). 2000. IUCN Guidelines for the Prevention of Biodiversity Loss Caused by Alien Invasive Species. IUCN Species Survival 
Commission (SSC), ISSG (Invasive Species Specialist Group), Gland, 24 pp.

Kim, H., Y. L, Jang, and P. S. Park. 2014. Distribution pattern of Ageratina altissima along trails at Mt. Umyeon in Seoul, Korea. Korean Journal of Agricultural and Forest Meteorology 16: 227-232.

Kim, K.-J. 2007. Eupatorieae Cass. In The Genera of Vascular Plants of Korea. Park, C.-W. (ed.), Academy Publishing Co., Seoul. Pp. 1006-1009.

Kim, K.-J. 2019. Eupatorieae Cass. In The Genera of Vascular Plants of Korea. Park, C.-W. (ed.), Academy Publishing Co., Seoul. Pp. 1336-1341. (in Korean)

King, R. M. and H. Robinson. 1970. Studies in the Eupatorieae (Compositae). XIX. New combinations in Ageratina. Phytologia 19: 208-229.

King, R. M. and H. Robinson. 1987. The genera of the Eupatorieae (Asteraceae). Monographs in Systematic Botany 22: 1581.

King, R. M., D. W. Kyhos, A. M. Powell, P. H. Raven and H. Robinson. 1976. Chromosome numbers in Composite. XIII. Eupatorieae. Annals of the Missouri Botanical Garden 63: 862888.

Lee, T. B. 2003. Coloured Flora of Korea. Vol. 2. Hyangmunsa, Seoul, 910 pp. (in Korean)

Lee, Y. N. 2006. New Flora of Korea. Vol. 2. Kyohaksa, Seoul,
883 pp. (in Korean)

Lee, W.-T. and Y. J. Yim. 1978. Studies on the distribution of vascular plants in the Korean Peninsula. Korean Journal of Plant Taxonomy 8(Appendix): 1-33. (in Korean)

Linnaeus, C. 1753. Species Plantarum. Vol. 2. Laurentius Salvius, Stockholm, $1200 \mathrm{pp}$.

Linnaeus, C. 1774. Systema Vegetabilium, 13th ed. Murray, J. A. (ed.), Typis et impensis Jo. Christ. Dieterich, Göttingen.

Linnaeus, C. f. 1781. Supplementum Plantarum. Impensis Orphanotrophei, Brunsvigae, $467 \mathrm{pp}$.

Nesom, G. L. 2006. Ageratina. In Flora of North America North of Mexico. Vol. 21. Flora of North America Editorial Committee (ed.), Oxford University Press, New York and Oxford. Pp. $547-552$.

Park, S. H. 2009. New Illustrations and Photographs of Naturalized Plants of Korea. Ilchokak, Seoul, 575 pp. (in Korean)

Reichard, J. J. 1780. Systema Plantarum. Vol. 3. Frankfurt, 972 pp.

Schilling, E. E., J. L. Panero and P. B. Cox. 1999. Chloroplast DNA restriction site data support a narrowed interpretation of Eupatorium (Asteraceae). Plant Systematics and Evolution 219: 209-223.

Schmidt, G. J. and E. E. Schilling. 2000. Phylogeny and biogeography of Eupatorium (Asteraceae: Eupatorieae) based on nuclear ITS sequence data. American Journal of Botany 87: 716-726.

\title{
미국등골나물과 서양등골나물(국화과: 등골나물족)의 분류학적 검토 \\ 오상훈* \\ 대전대학교 생명과학과
}

\begin{abstract}
적 요: 서양등골나물은 우리나라에서 생태계 교란 생물로 지정된 외래 침입종이다. 북아메리카 동부지역이 원산지인 이 외래 식물에 대해 각각 2개의 학명(Eupatorium rugosum Houtt., Ageratina altissima (L.) R. M. King \& H. Rob.)과 국명(서양등골나물 및 미국등골나물)이 혼용되고 있어 분류학적 혼란을 초래하고 있다. 이 논문에서는 이들의 분류학적 실체와 내력을 밝혀 분류학적 혼란을 해결하고자 하였다. 조사 결과, 미국등 골나물과 서양등골나물은 동일한 분류군으로서 린네가 Species Plantarum에 Ageratum altissimum으로 처음 기재한 종이다. 이 종은 Eupatorium속으로 전이되어 대체명이 공표되고 이후 Ageratina속으로 전이되었다. 즉, Eupatorium속에서는 전혀 다른 기준표본에 근거해 이미 존재하였던 E. altissimum L. 때문에 대체명으로 E. rugosum이 공표되었고, Ageratina속에서는 종소명 'altissima'를 사용하고 있던 종이 없었기 때문에 원명에 근거해 A. altissima의 학명이 공표되었다. 이러한 과정에서 발표된 이름들이 국내에서는 서로 다른 분류군으 로 인식되면서 분류학적 혼란이 야기된 것으로 사료된다. 형태 및 분자 형질을 분석한 연구 결과에 근거해 서양등골나물의 정명은 A. altissima이다.
\end{abstract}

주요어: 등골나물아재비속, 서양등골나물속, 등골나물속, 서양등골나물, 분류학적 혼란 